scratch in one place. A little pressure increases incentive, but it is undesirable to produce anxiety about changing jobs just as the period of maximum study has arrived, particularly for overseas trainees. Six different rotational programmes were devised, with two trainees appointed to each. Most trainees enter as beginners, but the system allows people of varying experience to be appointed to a place in the programme appropriate to their needs. The last six months is a period of flexibility for those who are coming to the end of their training and allows some informal exchanges of post to gain experience omitted elsewhere.

The major branches of psychiatry are represented. Six months each are given to psychogeriatrics and child-adolescent psychiatry, the latter being combined with experience in mental handicap of one day per week. The specialties are neurology (one month attachment to DGH Department), psychology (one month attachment to Area Department based at Exe Vale), alcoholism (short attachment to Area Unit) and forensic psychiatry and administration, in which trainees gain experience by arrangement with their consultant, this being noted in their record books.

Each trainee on appointment receives a programme number and a personal, up to 42-month, timetable. All concerned are able to trace exactly where and with whom the trainee will be working until the 42 nd month. Some weeks in advance of changes staff movement notices are circulated to remind teams that a trainee is leaving or joining and so that the personnel and finance departments can take the necessary administrative steps.

Trainees are attached to personal tutors throughout their stay, receive induction tutorials during their first six weeks from senior registrars and are interviewed by the Psychiatric Tutor who gives them a package containing useful information, reading lists, history taking schedules, etc, and a training record book containing details of the rotational training scheme, a curriculum vitae, and sections for recording experience gained or missed and examination results. The books can be presented for inspection when applying for subsequent posts.

\section{Conclusions}

The scheme has worked well, and I believe that it has contributed to a more ready acceptance of movement amongst medical staff. One complaint about staff rotation is lack of continuity, and though this has not been completely overcome all trainees do spend one period of at least 18 months in the same placement. All changes in individual teams overlap by at least three months, which is important for shorttenure posts such as child psychiatry. Both trainees do not move on the same day.

There is reasonable flexibility in the system, which probably strikes the right balance between rigidity and chaotic informality. Clinical assistant and other posts which rotate more slowly cushion any hiccoughs, the most common being failures to make new appointments. The smaller or short-tenure teams do need this cushion, and this is really a plea in favour of the experienced sub-consultant.

To say that the mechanics of this scheme are about right is not to say the same about the content. The period in mental handicap is inadequate and will be increased to three months whole-time when a new post is funded. Formal psychotherapy training is also deficient, and unless it is to be taught entirely by nonmedical psychotherapists, as at present, will only improve with a change of central policy. If good training schemes and constant monitoring and administering as well as good teaching are genuinely thought to be desirable, those organizing them should be enthusiastically enabled to do so.

\title{
MEDICAL STUDENTS IN PSYCHIATRIC OUT-PATIENTS
}

By C. J. Salisbury and G. L. Harrison

A good doctor-patient relationship is central to the task of gathering information and providing treatment, especially in psychiatry. In a teaching hospital this relationship may be complicated by the presence of one or more medical students, watching in an uninvolved fashion, and possibly changing from visit to visit. If the students are seated to one side or even behind him, the patient may feel increasingly uncomfortable about exposing personal material in the absence of any visual feedback. A passive audience may be permissible in a general medical setting where information is less personal and amateur status is masked behind white uniforms. In psychiatry, however, the youthfulness and comparative immaturity of students may be heightened by casual dress and less formal clinics. 
We wondered whether patients felt significantly inhibited by medical students, and if so whether they would prefer alternative teaching methods, such as video or a one-way screen. Several authors have commented on the lack of communication between doctors and patients, and various aspects of this also interested us: were patients expecting to have students present; did they know they could object; and were they given the opportunity at interview to do so?

\section{Patients and methods}

In psychiatric out-patient clinics in Bristol, medical students are present in groups of two or three, seated to one side or behind the doctor. Interviews are usually observed passively, although in one clinic a student may be asked to see a patient beforehand.

One hundred patients from clinics in two Bristol hospitals (three different consultants) were asked to complete a ten-part questionnaire while waiting for their consultation. Although the impersonal nature of a written questionnaire has obvious weaknesses, it may encourage an honest expression of attitudes. The questions used are given in full with the results. All new psychiatric out-patients in Bristol are sent a form with their appointment stating that they may see students and that if they wish they may object. Questions 5-7 relate to this.

\section{Results}

Out of the original 100 patients, two were unable to answer the questionnaire because of poor sight, and four returned it uncompleted. Questions 1 and 2 showed that the remaining 94 patients sub-divided into three groups:

(a) Patients on their first visit to a psychiatric outpatient clinic ( 35 per cent of total).

(b) Follow-up patients who had not had students present at any previous visits (21 per cent total).

(c) Follow-up patients who had previous experience of students ( 44 per cent).

All figures given are the percentage of the total number of patients in that sub-group, unless otherwise specified.

\section{Question 3}

Would you prefer to go to an

out-patient clinic in:

(a) A teaching hospital, where students may be present

(b) A non-teaching hospital, where students will not be present

(c) No preference
All
(a) (b) (c)

$\begin{array}{llll}22 & 30 & 15 & 19\end{array}$
Question 4

$\underset{\text { Patients }}{\text { All (a) (b) (c) }}$

In a teaching hospital, where students may be present, which would you prefer:

(a) To have students in the consulting room with the doctor, as happens at present

(b) To be seen by the doctor alone, while being recorded on TV for students to watch the film later

$\begin{array}{llll}45 & 39 & 40 & 51\end{array}$

(c) To have students in an adjacent room where they could see you, but you could not see them (through a 'one-way' screen)

(d) No preference

(e) I would object to students being present or seeing my consultation in any way (No answer)

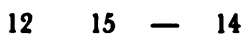

$\begin{array}{llll}10 & 12 & 10 & 7\end{array}$

$\begin{array}{llll}24 & 18 & 30 & 26\end{array}$

$7 \quad 920-$

Question 5

Were you expecting there to be medical students with the doctor today?
(a) Yes
(b) No
(c) Don't know

$\begin{array}{llll}28 & 27 & - & 41 \\ 47 & 46 & 80 & 32 \\ 25 & 27 & 20 & 27\end{array}$

Question 6

If so, approximately how many?

(Percentage of those who answered yes above)
(a) One
(b) Two to four
(c) Five to ten

$\begin{array}{llll}37 & 24 & 80 & 38\end{array}$

$53 \quad 59-59$

$\begin{array}{llll}6 & 6 & 20 & 3\end{array}$

$\begin{array}{llll}\text { All (a) (b) (c) } & \end{array}$

(d) Eleven to twenty

(e) More than twenty

(No answer)

$\overline{-} \overline{-}=-$

Question 7

Did you know that you could ask not to have students present, if you very much objected?

(a) Yes

(b) No

(No answer)

$\begin{array}{rrrr}59 & 64 & 30 & 71 \\ 37 & 27 & 70 & 29 \\ 4 & 9 & - & -\end{array}$

The following two questions are only applicable to follow-up patients who have seen students on previous visits

Question 8

percentage of $(c)$

On your last visit when students

were present, did you feel you were

given the opportunity to refuse to

see medical students?

(a) Yes

69

(b) No 
Question 9

Were there things relating to your problem that you did not feel able

(b) Yes, because I did not feel at

(c) Yes, because I did not feel that to tell the doctor?

(a) Yes, because I did not feel at ease with the doctor ease because the students were present the doctor would be interested, or that it would be relevant

(d) Yes, because I felt it was personal, and not the business of anyone else

Percentage of those answering 'yes'

6

14

10

6

All Patients

(e) No, I felt able to tell the doctor everything about my problem. even though the students were present

(No answer) patients did not realize that students might be present at their interview, and 9 per cent would find this objectionable. It is difficult to know how to rectify this, as information is already sent out to every new patient. Skuse (1975) has shown that patients who are informed about what to expect in psychiatric outpatients are twice as likely to attend subsequently as those who are not. The information in Skuse's study, however, was personally conveyed, and the apparent ignorance of so high a proportion of new patients in the present study confirms the limited value of written communication. We must agree with Michaels and Sevitt (1978) when they recommend that general practitioners should spend more time explaining what to expect in psychiatric out-patients at the time of referral. This problem of lack of communication between doctor and patients is highlighted in Reynolds' (1978) study of surgical patients at another Bristol hospital.

Thirty-seven per cent of patients in our study did not know that they could object to the presence of students. This is a controversial issue, and the 'right' of patients to refuse to see students in a teaching hospital is not always supported by medical staff. Although it is hospital policy in Bristol to tell patients that they may refuse, 31 per cent did not feel they were offered the opportunity at interview. This study suggests that overall only 7 per cent of patients would object to students. A personal reminder would possibly do much to clear up patients' expectations, with little actual loss of teaching material.

\section{Acknowledgements}

We would like to thank the psychiatric clinic receptionists for help in distributing questionnaires, and $\mathrm{Dr}$ M. G. Barker. Consultant Psychiatrist, for his advice about the original project.

\section{REFERENCES}

Michaels, R. M. \& Sevitt, M. A. (1978) The patient and the first psychiatric interview. British Joumal of Psychiatry, 132, 288-292.

Reynolds, M. (1978) No news is bad news: patients' views about communication in hospital. British Medical Journal, $i$, 1673-1767.

SXUSE, D. H. (1975) Attitudes to the psychiatric out-patient clinic. British Medical Journal, iii, 469-477.

present teaching method, with two or three students sitting in the consulting room with the doctor seems satisfactory, both in terms of practicality and patient acceptance.

Patients are not, however, very well informed with regard to medical students. Forty-six per cent of new

\author{
C. J. SAlisbury \\ House Officer in Medicine, Frenchay Hospital, Bristol \\ GLYNn L. Harrison \\ Registrar in Psychiatry, Bristol General Hospital
}

